\author{
Christiane S. Hartog \\ Anders Aneman \\ Bara Ricou
}

\section{Increasing participation in critical care studies: the need to understand surrogate decision-makers for critically ill patients}

Received: 10 December 2014

Accepted: 13 December 2014

Published online: 9 January 2015

(C) Springer-Verlag Berlin Heidelberg and ESICM 2015

C. S. Hartog (®)

Department of Anesthesiology and Intensive Care Medicine, Centre for Sepsis Care and Control, Jena University Hospital, 07747 Jena, Germany

e-mail: Christiane.hartog@med.uni-jena.de

Tel.: +49-3641-9323171

\section{A. Aneman}

Intensive Care Unit, Liverpool Hospital and University of New

South Wales, Sydney, Australia

\section{B. Ricou}

Intensive Care of Geneva, Department of Anesthesiology,

Pharmacology and Intensive Care, University Hospitals of Geneva and University of Geneva, Geneva, Switzerland

Clinical research is necessary to improve and evolve the care provided to current and future critically ill patients. Only a minority of patients admitted to the intensive care unit (ICU) are capable of providing informed consent for themselves [1] and, consequently, the vast majority of patients are enrolled in clinical studies following informed consent provided by substitute (surrogate) decision-makers (SDMs). The European Union Directive on Clinical Research (2001/20/EC) regulates the process of informed consent to include prior consent by a legal representative for non-urgent medical research [2]. However, in exceptional research situations-a not uncommon situation in the ICU-consent may be waived or deferred. National legislation in such situations is variable or even lacking and is currently being examined by both the European Parliament and European Council [3].
Time constraints imposed by the urgency and acuity of critical illness, as well as the perceived or real risk associated with invasive procedures and therapeutic interventions employed in the ICU, are well recognised, with the result that SDMs are less inclined to provide consent, thereby possibly increasing the risk for discrepancies between the wishes of the patient and those of the SDM $[4,5]$. To date, only limited data are available to assist healthcare professionals to understand the processes involved when approaching SDMs. For both patients and SDMs, the critical care situation is emotionally burdensome, affects cognition and, thereby, the capacity to understand and retain the critical information provided by the healthcare professionals [6]. An observational study in elective cardiac surgery patients which assessed the effect of a formalised informed consent procedure found that although $80 \%$ of patients recalled-after 10-12 daysthat they had been enrolled into a clinical study during their ICU stay, only $32 \%$ of them were able to remember the purpose and the risks of the clinical trial [7]. The authors attributed the low rate of complete recall in their study to the difficulty of ICU patients to process information given the stress and feelings of dependence and anguish. In order to truly respect patient autonomy, the authors concluded that informed consent is a process which may require multiple conversations on several occasions during the period the research is being conducted [7]. The same authors presented hypothetical research scenarios to patients and relatives at discharge from the ICU and reported that a majority of the patients and relatives thought that at least two persons should provide consent [8]. It would therefore appear that sharing the decision of informed consent with a second person may facilitate participation in ICU research. Another important aspect of the consent process is the potential discrepancy between decisions made by SDMs and those that the patients would make [9], with one study demonstrating that up to one-third of the decisions made by 
SDMs may not accurately represent the patient's wishes in terms of enrolment in clinical research trials [10]. It is obvious that primary research on all aspects of the consent process affecting enrolment into critical care studies is much needed. A cross-sectional study of research practices in 23 Canadian ICUs found that more than one-half of all opportunities to recruit patients were missed or considered infeasible as a result of research team workload, narrow time windows for inclusion, difficulties in contacting families, non-existent SDMs, physician refusals, and protocols prohibiting co-enrolment [1]. It is crucial for the scientific validity of clinical trials to maximise the potential for enrolment and to minimise missed opportunities. It is equally crucial to ensure that the patient's autonomy and wishes are fully respected and safeguarded.

The well-designed mixed-method study by Burns et al. recently published in Intensive Care Medicine [11] questions the need for a physician to obtain consent from SDMs for enrolment of a patient in a clinical trial. The pilot feasibility trial evaluated a physician (MD)-versus a non-physician (non-MD)-led approach to SDMs for obtaining consent for research. A nested qualitative study evaluated the experiences of SDMs in being approached for consent. The authors did not find any differences in consent rates between the two approaches or in the investigator- or SDM-assigned study risk. The nested qualitative study did, however, identify poor SDM recall of physician involvement, which further suggests that physicians are not a mandatory factor in the informed consent procedure. The only factor which enhanced the rate of consent was the inclusion of a clinical update on the patient's condition at the time of approaching the SDM. This result underlines the importance of SDMs in the relationship based on the clinical situation of the patient but also the risks of therapeutic misconception [12].

A most interesting finding in this study was the feelings of SDMs that physician involvement in initial research encounters was inconsequential and that they preferred physicians' time be dedicated to providing patient care. This finding suggests that in contrast to what is commonly felt by the physicians, SDMs do not expect to be approached by the physician him/herself and would actually
Table 1 Some key messages from previous reports (inspired from the findings of Chenaud et al. [7])

Informed consent should be obtained before admittance into the intensive care unit whenever possible

Participants should be encouraged to read the informative leaflet and ask questions

The investigators should consider repeating the informed consent procedure during an ongoing clinical trial in order to respect patients' rights

Informed consent to participate in a clinical trial should be considered an ongoing process rather than a single procedure

accept a delegate. In the context of a shortage of ICU physicians burdened by an increasing clinical workload [13], the results of the study suggest alternative ways for ICU physicians to lead studies concommitantly with clinical commitments. The delegates who seek informed consent should, however, be aware of the need of SDMs for (detailed) clinical information on their loved ones.

The results of the study by Burns et al. [11] highlighting non-physician-led approaches need to be viewed in the appropriate local medico-legal and cultural context. Applicable law might limit the capacity of non-physicians to obtain consent, and entrenched trust in authority or traditions might furthermore act as barriers. Research ethics require that adequate information on the study in question is given with a complete disclosure of the risks and benefits, assuring patient comprehension and the voluntariness of consent. Researchers must also reliably assess each patient's decision-making capacity to avoid the errors of either asking subjects for consent who lack capacity or asking SDMs for consent when the patient is able to decide on his/her own.

This study adds to previous reports (Table 1) on ways to clarify, secure and enhance consent for clinical research. It will hopefully inspire and generate further, much needed research relevant to conducting scientific studies during the challenging circumstances of critical illness. This will undoubtedly benefit patients, their loved ones and the practice of intensive care medicine.

Conflicts of interest None.

\section{References}

1. Burns KE, Zubrinich C, Tan W, Raptis S, Xiong W, Smith O, McDonald E, Marshall JC, Saginur R, Heslegrave R, Rubenfeld G, Cook DJ, Canadian Critical Care Trials G (2013) Research recruitment practices and critically ill patients. A multicenter, cross-sectional study (the consent study). Am J Respir Crit Care Med 187:1212-1218
2. Lemaire F, Bion J, Blanco J, Damas P, Druml C, Falke K, Kesecioglu J, Larsson A, Mancebo J, Matamis D, Pesenti A, Pimentel J, Ranieri M (2005) ESICM task force on legislation affecting clinical research in the critically ill patient. The European Union directive on clinical research: present status of implementation in EU member states' legislations with regard to the incompetent patient. Intensive Care Med 31:476-479
3. Kompanje EJ, Maas AI, Menon DK, Kesecioglu J (2014) Medical research in emergency research in the European Union member states: tensions between theory and practice. Intensive Care Med 40:496-503. doi:

10.1007/s00134-014-3243-6 
4. Barrett KA, Ferguson ND, Athaide V, Cook DJ, Friedrich JO, McDonald E, Pinto R, Smith OM, Stevenson J, Scales DC (2012) Surrogate decision makers' attitudes towards research decision making for critically ill patients. Intensive Care Med 38:1616-1623

5. Mehta S, Pelletier FQ, Brown M, Ethier C, Wells D, Burry L, MacDonald R (2012) Why substitute decision makers provide or decline consent for ICU research studies: a questionnaire study. Intensive Care Med 38:47-54

6. Coppolino M, Ackerson L (2001) Do surrogate decision makers provide accurate consent for intensive care research? Chest 119:603-612

7. Chenaud C, Merlani P, Luyasu S, Ricou B (2006) Informed consent for research obtained during the intensive care unit stay. Crit Care 10(6):R170

8. Gigon F, Merlani P, Chenaud C, Ricou B (2013) ICU research: the impact of invasiveness on informed consent. Intensive Care Med 39:1282-1289
9. Newman JT, Smart A, Reese TR, Williams A, Moss M (2012) Surrogate and patient discrepancy regarding consent for critical care research. Crit Care Med 40:2590-2594

10. Shalowitz DI, Garrett-Mayer E, Wendler D (2006) The accuracy of surrogate decision makers: a systematic review. Arch Intern Med 166:493-497

11. Burns KEA, Rizvi L, Smith OM, Lee Y, Lee J, Wang M, Brown M, Parker M, Premji A, Leung D, Hammond Mobilio M, Gotlib-Conn L, Nisenbaum R, Santos M, Li Y, Mehta S (2015) Is there a role for physician involvement in introducing research to surrogate decision makers in the intensive care unit? (The approach trial: a pilot mixed methods study). Intensive Care Med 41:58-67. doi:10.1007/s00134-014-3 558-3
12. de Melo-Martin I, Ho A (2008) Beyond informed consent: the therapeutic misconception and trust. J Med Ethics 34:202-205

13. Health Resources and Services Administration (HSRA) (2006) The critical care workforce: a study of the supply and demand for critical care physicians. Available at: http://www.m cvanderbiltedu/documents/CAPNAH/fil es/criticalcarepdf 